\title{
$=\mathrm{T} R A M A=$
}

\section{ENSINO-APRENDIZAGEM DE LÍNGUA DE HERANÇA: EXPERIÊNCIAS LINGUÍSTICAS, MEMÓRIA FONOLÓGICA E IDENTIDADE CULTURAL}

\author{
Denise Barros Weiss (UFJF) ${ }^{1}$ \\ Maíra Candian de Paula Dutra (UFJF)²
}

\begin{abstract}
RESUMO: A partir de análises que constataram que falantes de Língua de Herança (LH), ao estudarem a língua na fase adulta, produziam elementos fonéticos/fonológicos relacionados à variante da região de origem dos pais, que foram aprendidos na infância, apresentamos nesse artigo repercussões desse resultado de pesquisa para as famílias e para os professores de línguas de herança. Para isso, utilizamos Cummins (1983), com o conceito de LH, Gontijo e Silva (2016) e Souza (2016), que estudam o ensino de LH em diferentes contextos. Também nos baseamos em Izquierdo et al (2013) e Xavier (2013), para compreendermos aspectos da memória humana e em Fonseca, Weiss e Dutra (2018), que observaram os indícios da atuação da memória fonológica no registro da fonética das línguas aprendidas na primeira infância. O aluno de língua de herança tem nessa memória fonológica uma vantagem - uma marca que lhe confere uma identidade cultural, e uma habilidade valorizada na proficiência em L2.
\end{abstract}

PALAVRAS-CHAVE: Fonética/Fonologia. Língua de Herança (PH). Memória. Ensino de Língua de Herança.

\begin{abstract}
Based on analyses which demonstrate that heritage language (HL) speakers, when learning the language in mature age, produce phonetic/phonological traits related to the language variety from their parents' place of origin that were learned in early childhood, this study presents the implications and potential pedagogy issues concerning teachers and families of HL speakers. In order to do that, we used the following theoretical references: Cummins (1983), the first on approaching HL concept, Gontijo and Silva (2016) and Souza (2016), who study HL teaching in different contexts. Also, we founded in Izquierdo et al (2013) and Xavier (2013) in order to comprehend human memory features, along with Fonseca, Weiss, and Dutra (2018), who observed the evidence of phonological memory performance in a phonetic record of languages learned in early childhood. The HL student has in this phonological memory an advantage - a cultural identity imprint, and an esteemed ability in L2 proficiency.
\end{abstract}

KEYWORDS: Phonetic/Phonological. Heritage Language (HL). Memory. Heritage Language Teaching.

\section{INTRODUÇÃO}

O conceito de língua de herança (doravante LH) se refere à linguagem etnocultural de uma comunidade, a qual não é necessariamente a primeira língua aprendida pela criança ou nem mesmo usada no ambiente familiar ${ }^{3}$. Essa língua tem a característica de ser transmitida exatamente como uma herança propriamente dita: assim, passa de pais emigrantes para seus filhos que nascem/crescem em um país de língua diferente da dos pais (CUMMINS, 1983; LICO,

\footnotetext{
${ }^{1}$ Professora adjunta da Universidade Federal de Juiz de Fora, no departamento de Letras, atuante na área de estudos linguísticos sobre o ensino de português para estrangeiros. E-mail: dbweiss@uol.com.br

${ }^{2}$ Mestranda do curso de Pós-graduação em Linguística da Universidade Federal de Juiz de Fora. E-mail: maira_dutra@hotmail.com

${ }^{3}$ Cf:: "Heritage language generally refers to the community ethnocultural language which is not necessarily the child's first-learned language (or even used in the home)." (CUMMINS, 1983, p.7). (Todas as traduções são de nossa autoria, salvo aquelas mencionadas em nota).
} 


\section{$=$ TRAMA $=$}

2001; SOUZA \& BARRADAS, 2013; FLORES \& MELO-PFEIFER, 2014). Dessa forma, a língua de herança "apresenta os seguintes traços: é uma língua minoritária, usada em esferas restritas, predominantemente como língua oral e coloquial." (DOI, 2006, p. 68). Pode-se dizer da LH, para além disso, que seus falantes podem apresentar níveis de proficiência diversos e "experiências de aquisição/aprendizado e de contato [...] bastante variadas" (FLORES \& MELOPFEIFER, 2014, p. 18).

Essa situação é algo recorrente ao longo de toda a trajetória humana, considerando que sempre houve migração e que essa condição tenha se dado nas mais diferentes situações - guerras, fome, peste, por um lado, ou novas oportunidades, chance de menos perseguição religiosa, por outro. Entretanto o estudo sistemático dessa situação de contato linguístico é bastante recente.

O termo foi cunhado por Cummins em um texto de 1983. Daí por diante, o fenômeno vem sendo estudado ao longo dos anos, principalmente nos Estados Unidos e no Canadá.

Nesse artigo, tratamos especificamente da situação do Português como Língua de Herança (doravante PLH), mas consideramos que as análises aqui apresentadas tenham relevância em muitos outros contextos de língua de herança. Pretendemos mostrar, a partir de análises empíricas e estudos realizados no âmbito dessa área, que há indícios da existência de uma memória fonológica adquirida na primeira infância (FONSECA, WEISS \& DUTRA, 2018). Nessa memória armazena-se, inconscientemente, a habilidade fisiológica de pronunciar os sons da língua. A memória fonológica está relacionada à memória procedural; a partir de repetições padronizadas, preserva os dados aprendidos e os evoca através do desempenho (IZQUIERDO et al., 2013).

Apresentaremos os resultados de um experimento realizado com três informantes norte-americanas que são falantes de PLH, a partir de amostras de produção oral, para se observar como essas falantes empregam as variantes do português. A hipótese é de que elas utilizem as variantes fonéticas oriundas da aquisição inicial da língua, quando crianças, a partir de input gerado pela interação em português com o progenitor brasileiro. Parte desses dados foi analisada previamente no artigo publicado em 2018 (FONSECA, WEISS \& DUTRA, 2018). Nesta publicação, acrescentamos a esses os dados de mais informantes e focamos nas possíveis repercussões dessa descoberta para o ensino de língua de herança.

$O$ artigo se estrutura da seguinte forma: inicialmente, discorremos brevemente sobre os processos biológicos envolvido na formação da memória em um indivíduo, destacando o papel da memória procedural - locus onde se estabelece a informação sobre a fonologia da língua materna. A seguir, mostramos como um experimento de gravação e análise da leitura de frases por alunos de português que são falantes dessa língua como LH pode nos mostrar que a fonologia da língua materna, convertida em língua de herança pelo esquecimento e desuso ao longo de muitos anos, ainda persiste na fala. Finalmente, mostramos as repercussões dessa observação nos contextos da família e da escola.

\section{MEMÓRIA PROCEDURAL}

A memória procedural (ou processual) é "um tipo de memória implícita ou não declarativa cuja evocação se dá por meio do desempenho em vez da lembrança ou do reconhecimento conscientes" (BADDELEY, ANDERSON \& EYSENCK, 2011 p. 23). Ela é chamada de não declarativa, pois não se sabe de onde vem essa capacidade. A lembrança ocorre, então, a partir de estímulos ou de links de semelhança, por exemplo, "adivinhar uma palavra inteira, a partir da apresentação de suas partes" (OLIVEIRA, SILVA \& LEITE, 2013, p. 21), ou cantarolar toda a letra de uma música da qual já não se lembrava mais, a partir da escuta só da melodia. O armazenamento dos dados obtidos a partir da aquisição de habilidades 


\section{$=$ TRAMA $=$}

se dá por meio da repetição de uma atividade que segue um mesmo padrão. A persistência das memórias procedurais é muito grande, podendo perdurar por décadas (IZQUIERDO et al, 2013).

A produção de fonemas da língua materna se dá por um sistema autônomo, sobre o qual se tem pouco ou nenhum controle - só quando queremos imitar outro sotaque é que conscientemente usamos outro fone, dentro dos disponíveis na grade de variação da língua naquele contexto. A aquisição desse componente da língua se dá por imitação e começa muito cedo na vida do bebê. Essa informação é processada como memória procedural.

Se a memória fonológica é de caráter procedural, pode-se inferir que, caso ela seja evocada mesmo muito tempo depois de ter-se feito isso pela última vez, os movimentos da musculatura que compõem a articulação dos fonemas será recuperado, assim como acontece com outras habilidades aprendidas mecanicamente e jamais esquecidas (andar de bicicleta é o exemplo clássico). Pensando agora especificamente na situação de LH, é possível dizer que ao se retomar o uso de uma língua materna que se tornou língua de herança, o componente fonético/fonológico será muito mais facilmente reproduzido que outros, tais como o morfológico ou sintático.

Para verificar se essa hipótese tem validade, preparamos um experimento com essa finalidade específica. É o que apresentaremos na próxima seção.

\section{O EXPERIMENTO}

O projeto piloto, chamado de Memória fonológica no aprendizado de L2, foi iniciado na graduação, como iniciação científica financiada pela Universidade Federal de Juiz de Fora, e continuado como projeto de mestrado. As informantes desse projeto piloto foram escolhidas por serem antigas colegas de uma das autoras, que já tinha conhecimento de que eram falantes de português como língua de herança. Elas se caracterizam por serem norte-americanas, com idade entre 21 e 24 anos, uma filha de pai brasileiro de Minas Gerais e outra filha de mãe brasileira de Alagoas, e que aprenderam o PB na infância, no ambiente familiar, ou seja, de não imersão. As participantes relataram ter contato com a língua desde a infância e se comunicar com os parentes e amigos brasileiros apenas em português. Ao ingressarem na universidade, tiveram a experiência de estudar a língua de maneira formal com uma professora de origem havaiana. (FONSECA, WEISS \& DUTRA, 2018, p.1281).

O trabalho se deu em duas fases. Na primeira, foram coletadas informações a partir de um formulário respondido online. Essas informações mais específicas tinham como objetivo saber a relação delas com a língua portuguesa. Em um momento posterior, através de chamadas online por Skype (devido à distância geográfica), aplicamos um protocolo de interação no PowerPoint que continha 25 frases e imagens de contextualização. Foi orientado às participantes apenas que lessem as frases em voz alta, na tentativa de garantir uma maior espontaneidade na pronúncia das frases e expressões. A gravação desses dados foi realizada com um gravador de alta sensibilidade e resultou no corpus disponibilizado.

Pretendíamos investigar, nas falas das informantes, aspectos fonéticos e fonológicos do PB, bem como variações dialetais regionais. Para tanto o foco recaiu sobre os seguintes tópicos: a) as vogais médias em posição pretônica; b) os fonemas /s/ e /r/ em posição coda; c) a produção de vogais nasais; d) a redução de vogais átonas e pós-tônicas; e e) a palatalização de consoantes. Os itens a) e b) correspondem a pontos de variação dialetal regional, enquanto c) diz respeito a um ponto de diferença fonética entre o Inglês (Língua Materna) e Português (Língua de Herança), e, por fim, d) e e) são características fonéticas gerais do PB (FONSECA, WEISS \& DUTRA, 2018, p. 1279-1280). "Tais variações dialetais fonético-fonológicas são marcas regionais que constituem parte da identidade linguística de comunidades de falantes" 


\section{$=$ TRAMA $=$}

(FONSECA, WEISS \& DUTRA, 2018, p. 1280), o que justifica a investigação sobre a presença ou não dessas marcas regionais nas produções de estrangeiras falantes de PLH.

Apresentamos aqui, além dos dados fornecidos por esse estudo inicial, os resultados de uma nova informante que se caracteriza por ter características semelhantes às das informantes anteriores: norte-americana de 20 anos, filha de mãe brasileira de São Paulo, aprendeu o Português no ambiente familiar na infância e teve aprendizado formal da língua com a mesma professora havaiana. Os dados dessa terceira informante foram obtidos com a aplicação do mesmo protocolo de leitura criado por Fonseca, Weiss e Dutra (2018), no qual a participante foi estimulada a pronunciar "palavras, frases e expressões, em português, previamente determinadas pelas pesquisadoras" (FONSECA, WEISS \& DUTRA, 2018, p. 1269).

No resultado da análise perceptiva dos dados, observamos que nossa informante produziu em suas falas, assim como as informantes do experimento inicial, características fonéticas relacionadas com a variedade dialetal da região de origem do progenitor brasileiro, além de características fonéticas mais gerais do PB.

Mostraremos primeiramente as características fonéticas gerais do PB observadas. As falas das três informantes foram caracterizadas pela boa produção de vogais nasais em palavras como "não", "muito", "em", "mãe", um traço fonético ausente no inglês e ponto de dificuldade recorrente para os falantes de Português como língua estrangeira. Além disso, todas as informantes reduziram o /e/ e o /o/ em posição pós-tônica, em palavras como "suco" e "hoje", ou como vogais em sílabas átonas.

A ditongação do núcleo da sílaba tônica seguido de /S/ pós-vocálico, em "três", "português", "dez", por exemplo, ocorreu nas falas das informantes com o PB herdado de Alagoas e de Minas Gerais, que demonstra ser a habilidade fonética delas com a língua semelhante à de um falante nativo. "A inserção de uma semi-vogal alta nesta posição é característica geral dos falares do PB." (FONSECA, WEISS \& DUTRA, 2018, p. 1287).

Como características fonéticas mais específicas da variedade dialetal herdada, temos a produção da informante que tem o PB de Alagoas como LH, na qual as vogais médias, em posição pretônica, sofreram variação dialetal regional, em "melão" e "modelo", por exemplo. Com /S/ em posição pós-vocálica também ocorre variação dialetal, quando ocorre a palatalização da fricativa em [iftu'der] (FONSECA, WEISS \& DUTRA, 2018, p. 1286).

O fenômeno de palatalização das oclusivas alveolares ocorre em várias regiões do Brasil, segundo Monaretto, Quednau e Hora (2001). Na pesquisa inicial, já havíamos observado que a palatalização de oclusivas alveolares diante do fonema /i/ ocorreu na produção da falante com o PB herdado de Minas Gerais, enquanto a falante que herdou o PB de Alagoas alternava: ora apresentando a palatalização, ora apresentando as oclusivas alveolares [d, t], que configura a pronúncia típica da região nordeste do Brasil. (FONSECA, WEISS \& DUTRA, 2018, p. 1286). Na produção da nossa informante com o PB herdado de São Paulo o fenômeno da palatalização de oclusivas alveolares diante de /i/ também foi observado, em palavras como "dia", "de", "sete".

Além disso, na produção da falante do PB de São Paulo, observamos o enfraquecimento de /R/ pós-vocálico, em "jantar", "supermercado", "tarde", por exemplo, que é um aspecto característico da pronúncia dessa região.

No experimento inicial, a análise das produções das informantes possibilitou constatar traços da variação dialetal correspondente a Minas Gerais e Alagoas, concluindo, então, que:

as participantes apresentam fortemente características de fala do português falado por um nativo brasileiro. Inclusive, há indícios fonéticos na fala das participantes da memória auditiva/processual da variedade do PB adquirida na primeira infância, ainda no contato familiar. Ao longo da aplicação do protocolo de 


\title{
$=$ TRAMA $=$
}

pesquisa, foi observado que, à medida que as participantes se sentiam mais à vontade com a tarefa, as características da variedade regional emergiam na sua fala, mostrando o aspecto afetivo da LH (FONSECA, WEISS \& DUTRA, 2018, p. 1281).

A produção da nossa informante com variedade herdada de São Paulo também demonstra capacidade fonética de produzir sons correspondentes à região de origem da mãe. Atribuímos essa capacidade à memória processual (IZQUIERDO et al, 2013), especificamente à chamada memória fonológica.

\section{REPERCUSSÕES DOS RESULTADOS DA PESQUISA}

Nosso objetivo nessa seção é apresentar contribuições para se pensar as implicações pedagógicas a partir do que observamos na análise de nossos dados, abrindo um caminho para futuras investigações, uma vez que é um assunto rico e complexo, não esgotando, assim, suas potencialidades de estudo. A possibilidade (que nos afigura plausível) de que a criança que aprende uma língua na primeira infância mantém uma habilidade de pronunciar os fonemas daquela língua como um nativo, mesmo quando ela própria julga ter esquecido completamente a língua, tem repercussões de várias ordens. Trataremos de duas delas que nos parecem muito relevantes. A primeira é o modo como se trata a língua de herança no âmbito familiar. A segunda é o tratamento que pode ser dado a esse componente linguístico no âmbito do ensino de língua de herança.

\section{REPERCUSSÕES PARA AS FAMÍLIAS}

A língua de herança, como já dissemos, é aprendida no contexto familiar, na primeira infância. Se um falante nativo, no ambiente em que a língua é majoritária, tem isso como algo corriqueiro e mesmo tão óbvio que jamais é sujeito a discussão, o mesmo não ocorre no contexto de língua de herança.

Em Xavier (2013) o autor discorre sobre as características da memória e sobre como sua formação no indivíduo é, ao mesmo tempo, determinante e determinada pelo ambiente social em que vive. A respeito da aquisição de memórias na primeira infância, recortamos essa fala do autor:

\begin{abstract}
entre os mamíferos, os infantes, usualmente indefesos, mantêm-se próximos dos seus cuidadores biológicos. Essa proximidade parece ser determinada por um sistema de apego que envolve padrões de respostas emocionais e comportamentais determinadas pela evolução filogenética do grupo, independendo, pelo menos nos estágios iniciais de desenvolvimento, de aprendizagem. Assim, grande parte das experiências no início do desenvolvimento ocorre na presença dos cuidadores biológicos. Nesse estágio, sistemas neurais responsáveis pela aquisição de conhecimento de natureza explícita (Xavier, 1993), que incluem estruturas do lobo temporal medial, ainda não estão plenamente formados. Esses fatos permitem explicar a "amnésia infantil", isto é, por que a maioria das pessoas não é capaz de recordar-se de experiências ocorridas antes dos 2 ou 3 anos de idade. A maciça aquisição de informações nesse estágio envolve experiências ocorridas com a participação intensa dos cuidadores. Face a esses aspectos relacionados ao desenvolvimento do sistema nervoso, não surpreende que experiências vividas nessa ocasião não sejam acessadas conscientemente. É certo que essas aquisições correspondem aos alicerces que definem a constituição e o funcionamento da rede nervosa em construção no sistema nervoso, com reflexos na vida adulta (XAVIER, 2013, p. 37)
\end{abstract}

Essa formação de memórias demonstra a relevância que tem o papel da família (ou os cuidadores biológicos, na terminologia de Xavier) na formação da identidade do indivíduo. No que diz respeito especificamente à aprendizagem da língua materna, observa-se que mesmo 


\section{$=$ TRAMA $=$}

que o indivíduo não se recorde mais tarde de ter adquirido determinados conhecimentos, eles estão lá e poderão ser ativados pela inserção da pessoa em atividades que se relacionam ou promovam essa evocação.

Uma relação intrínseca no contexto de LH é entre língua e identidade em falantes de PLH e seus pais. Ana Souza (2016) aborda esse tema, focando na influência que a imigração exerce nas identidades linguística e cultural de mães de falantes de PLH em Londres, e mostra que a forma como estas mães se veem e se sentem em relação à cultura brasileira diz muito sobre o modo como se relacionam com a língua e a cultura do país em que vivem atualmente. Isso quer dizer que o conceito de identidade social destas mães vai além de se sentirem brasileiras, pois é construído de acordo com o contexto em que estão inseridas, refletindo a realidade que experienciam.

Segundo Souza (2016), pelo viés da psicologia social e do pós-estruturalismo, identidade diz respeito ao "modo como os indivíduos se veem ligados a certas estruturas na sociedade, em termos de conhecimento e emoções" (SOUZA, 2016, p. 24), de forma que o afetivo e seus posicionamentos em relação à cultura e língua se refletem nas escolhas linguísticas destas mães. Desse modo, tem que haver nos pais "este entendimento sobre a relevância de transmitir a língua e cultura aos seus filhos, como forma de manter vivas suas origens" (LICO, 2011, sp), uma vez que a manutenção da LH depende, inicialmente, destes posicionamentos (SOUZA 2016), os quais repercutem na identidade dos filhos. Portanto, se a mãe dá importância ao PB na construção de sua identidade e se esforça em passar a língua materna aos filhos, é provável que o aprendizado e ensino sejam estimulados dentro e fora de casa (FONSECA, WEISS \& DUTRA, 2018, p. 1276).

Norton (2000 apud SOUZA 2016, p. 33-34) desenvolveu o conceito de investimento, o qual revela que "uma das motivações de imigrantes a aprender uma língua é a possibilidade de obter mais recursos linguísticos e culturais que os permitem negociar suas identidades na sociedade em que estão inseridos". Além disso, esse conceito permite ao falante de LH, alvo esse do nosso estudo, ter uma identidade mais complexa, que se altera de acordo com o período e local de suas interações sociais (SOUZA, 2016, p. 34). Nesse sentido, os conceitos de língua e identidade não só estão interligados como também são complementares e interdependentes, uma vez que a identidade pode ser construída como uma negociação nas relações sociais em ambientes linguísticos específicos, como em casa e nas salas de aula.

Sob o ponto de vista dos pais, é fundamental que eles saibam que a construção das memórias do filho começa muito cedo, ainda que ele próprio não reconheça isso mais tarde. Além disso, a ideia de que expor a criança muito jovem a mais de uma língua simultaneamente iria dificultar ou atrapalhar seu desempenho nelas não encontra base em nenhum estudo científico. Pelo contrário, apesar complexo e variado, o conceito de bilinguismo se consolida positivamente, demonstrando que a habilidade em duas ou mais línguas é favorável ao desenvolvimento da criança, como resume Brito (2011):

a ampla literatura na área do bilinguismo não permite mais uma visão negativa, como se ele representasse uma ameaça ao bom funcionamento cognitivo. Ao invés disso, há muitas evidências que sugerem que o bilinguismo tenha efeitos que o promovem e reforçam (BRITO, 2011, p. 24).

A plasticidade do cérebro e sua prontidão para adquirir as habilidades necessárias à aquisição de uma ou mais línguas estão muito ativas na fase jovem da vida. Klein et al (2014), em artigo no qual analisam a correlação entre a espessura cortical e o modo de uso das estruturas cerebrais em falantes monolíngues e bilíngues, sugerem que 


\section{$=$ TRAMA $=$}

a aquisição simultânea de duas línguas e o bilinguismo precoce são as condições associadas com a maior proficiência e apresenta o menor efeito na estrutura cerebral ligada ao monolinguismo. Nossos resultados mostram evidências estruturais de que a idade de aquisição é crucial na manutenção das estruturas para o aprendizado de língua. As maiores diferenças na estrutura cerebral associadas com aquisição tardia de L2 refletem o recrutamento de circuitos neurais subotimos para a aprendizagem de língua (KLEIN et al, 2014, p. 24) ${ }^{4}$.

Segundo Jasińska et al (2017), o bilinguismo expandiu a compreensão de como os contextos de aprendizagem influenciam a variabilidade e a plasticidade das bases neurais relativas ao aprendizado da leitura ${ }^{5}$.

Cabe à família decidir se essa criança receberá ou não o acesso a uma língua que é a da história da sua família. Manter o uso dessa língua, contudo, nem sempre é simples - é bastante comum que os pais sejam de nacionalidades diferentes e que por isso a língua majoritária acabe sendo a de comunicação dentro de casa, o que diminui muito as possibilidades de uso da língua minoritária com a criança.

A maneira como a língua minoritária é percebida pelos pais é determinante da maior ou menor vontade de se mantê-la. Se essa língua desperta uma memória positiva, ela terá valor para aquela família. Se, ao contrário, representa um passado que se pretende deixar para trás por alguma razão, considera-se que não há porque fazer o esforço de usar uma língua que não Ihes parece prestigiosa nem útil. Um fator relevante para essa decisão certamente é a maior ou menor ligação da família com uma comunidade que partilhe a língua que será de herança para a criança. O sentimento de pertencimento a uma comunidade, mesmo afastada do lugar onde aquela língua é majoritária incentiva o uso da língua e dá à criança oportunidades de uso social dela. Por outro lado, o sentimento resultante do isolamento daquele falante em uma comunidade que não valoriza aquela língua certamente contribui para um desânimo diante das poucas oportunidades de uso da língua fora do âmbito estritamente familiar. Uma família nessa situação tem menos motivos para se esforçar por manter viva a língua que trouxe consigo.

A pesquisa aqui apresentada demonstra que todo o esforço feito pela família ao conversar na língua de herança com as crianças, mesmo quando não parece muito eficaz, tem importantes repercussões futuras nas habilidades de fala. Mesmo quando a criança não se interessa por falar a língua, optando por responder na língua hegemônica (e isso é algo bastante comum), a exposição ao sotaque do familiar que usa aquela língua vai ser determinante para que ela desenvolva uma capacidade de fala muito semelhante, em termos das escolhas fonéticas, quando for aprender a língua, mais tarde - mesmo em idade adulta, como é o caso das jovens cuja fala foi analisada no experimento aqui relatado.

Assim, compreender que a língua é uma herança e que o conhecimento adquirido pela criança, mesmo quando abandonado durante anos, pode ser, ao menos em parte, recuperado em uma situação de aprendizagem da língua pode ser um alento para os que lutam para manter viva aquela língua no contexto familiar e um fator de convencimento para os pais que pensam ser isso uma perda de tempo e um desperdício de energia.

\footnotetext{
4 "Simultaneous acquisition of two languages and early bilingualism are the conditions associated with the greatest proficiency and show the smallest effect on brain structure relative to monolingualism. Our results provide structural evidence that age of acquisition is crucial in laying down the structure for language learning. The greater differences in brain structure associated with later sequential L2 acquisition might reflect recruitment of suboptimal neural circuits for language learning" (KLEIN et al, 2014, p.24). (Todas as traduções são de nossa autoria, salvo aquelas mencionadas em nota).

5 Cf: "bilingualism expands our understanding of how learning contexts impact the variability and plasticity of the neural bases for learning to read" (JASINSKA ET AL, 2017, p.42). (Todas as traduções são de nossa autoria, salvo aquelas mencionadas em nota).
} 


\section{$=$ TRAMA $=$}

\section{REPERCUSSÕES PARA OS PROFESSORES DE LÍNGUA DE HERANÇA}

Fatores emocionais se mostram decisivos quando o assunto é aprendizado de línguas e certa apreensão e ansiedade podem fazer toda diferença nesse processo, segundo Gontijo e Silva (2013). As autoras, após verificarem que "a ansiedade presente numa aula de língua estrangeira prejudica as habilidades de fala, de compreensão, de leitura e de escrita" (GONTIJO \& SILVA, 2013, p. 47), realizaram um estudo comparativo com turmas em duas universidades norte-americanas sobre a ansiedade no aprendizado de PLE e de PLH, analisando três fatores: apreensão comunicativa, ansiedade relativa a testes e receio de avaliação negativa. Elas concluíram que alunos de PLH, no geral, demonstraram menor nível de ansiedade do que alunos de PLE em relação a cada tipo de apreensão, o que não significa, porém, que não apresentem certa ansiedade. (GONTIJO \& SILVA, 2013, p. 56-57). Dessa forma, ambientes que proporcionem um alívio de ansiedade e que promovam a autoestima do aluno podem ser favoráveis ao aprendizado. De que maneiras, então, é possível estimular esses fatores emocionais e beneficiar o aprendizado dos alunos de PLH?

Primeiramente, é importante que a autoestima e confiança do aluno sejam elevadas, principalmente em situações de fala e compreensão oral, como forma de tentar amenizar a ansiedade em sala de aula. Cabe ao professor de LH "promover um sentimento positivo em relação à identidade dos seus alunos, examinando ostensivamente as suas características e o que elas significam" (SOUZA, 2016, p. 29). Como demonstramos anteriormente, a LH apresenta peculiaridades que se refletem no seu processo de ensino/aprendizado, dessa forma, no grupo pesquisado por Gontijo e Silva, alunos de PLH certamente se distinguem de alunos de PLE em vários aspectos.

Nesse artigo destacamos a capacidade de produção fonética (SOLÉ, 1981 apud GONTIJO \& SILVA, 2013, p. 49). Fonseca Weiss e Dutra (2018) e os novos resultados aqui apresentados mostraram indícios de que falantes de PLH possuem uma memória fonológica capaz de armazenar inconscientemente traços fonéticos, pois as informantes produziram foneticamente sons relativos à variação dialetal regional a que foram expostas na primeira infância (FONSECA, WEISS \& DUTRA, 2018, p. 1287). Verificamos que, se outros componentes da língua são perdidos ou esquecidos no tempo sem contato com o idioma, a memória fonológica está apenas adormecida, pois, assim que o falante de LH retoma o contato, a sua produção revela que esse componente está intacto na memória do aprendiz. Convém aqui fazer uma ressalva: se o componente fonológico permanece intacto, o mesmo não parece acontecer com o componente prosódico, provavelmente por ele estar ligado a uma manifestação de caráter mais sintático / semântico da língua. O processo de aprendizagem de LE, de modo geral, começa a partir de vocabulário simples, presente no cotidiano e na vida pessoal dos falantes, passando progressivamente a estruturas linguísticas mais complexas, as quais são derivadas da sintaxe com inserção da semântica. Já os aspectos fonéticos não costumam ser objeto de exercícios explícitos - a produção fonética é aprendida concomitantemente às estruturas vocabulares, sendo objetivo somente de treino mecânico. Paradoxalmente, esse aspecto da língua é muito valorizado. Mede-se comumente o nível de proficiência do aluno, de maneira intuitiva, pelo "sotaque". É assim muito comum ver o aprendiz de LE, em geral, dando muito valor à produção fonética, o que pode gerar uma sensação de frustração quando esse componente fonológico não é aprendido, mesmo que o aluno demonstre assimilação de outros componentes (morfológicos, sintáticos, semânticos, etc.).

Para nós brasileiros, essa situação pode ser exemplificada pela dificuldade que encontramos na produção dos sons das fricativas dentais não sibilantes surda /e/ e sonora / // no inglês (em palavras como "thick" e "that", respectivamente). Já os falantes de LH, assim como a produção da nossa informante e das informantes de Fonseca, Weiss e Dutra (2018) 


\section{$=$ TRAMA $=$}

evidenciaram, "chegam às aulas equipados com alguma habilidade de comunicação, especialmente oral" (SOLÉ, 1981 apud GONTIJO \& SILVA, 2013, p. 61).

Consideramos que a valorização dessa capacidade de produção fonética pode ser um fator de estímulo ao aprendiz de LH. Gontijo e Silva (2013) mostraram que alunos de PLH apresentaram níveis baixos de ansiedade em relação ao dialeto usado pelo professor de Português, possivelmente pelo maior contato com diferentes variedades do idioma, característica sociolinguística do grupo de PLH que se difere do grupo de PLE (GONTIJO \& SILVA, 2013, p.58). Sendo assim, se as variações dialetais de alunos e professores de LH não se encontrarem em concordância, isso não se configura um problema no aprendizado, o que corrobora com nosso argumento de que a capacidade de produção fonética dos alunos deve e precisa ser estimulada dentro de sala de aula e deve ser objeto de elogio e valorização por parte do professor. O docente sabe, por experiência, que isso não vai ser uma dificuldade para seu aluno, mas o aprendiz de LH não tem nenhuma ideia disso e não pode valorizar a vantagem que isso the dá desde o princípio do processo. Fornecer essa informação ao aluno e à sua família pode ser um fator de incentivo e até de quebra de preconceitos, já que o aluno às vezes escuta em casa que a língua que ele fala é inadequada e se envergonha por isso.

\section{CONSIDERAÇÕES FINAIS}

A língua de herança consiste em uma habilidade linguística com características específicas. Adquirida na primeira infância, no contato com a família e perdida por falta de uso devido às condições sociais em que se insere o falante, pode ser retomada mais tarde, na adolescência ou na idade adulta. Nessa retomada, uma vantagem do falante de LH é a memória fonológica que, ao que tudo indica, Ihe permite produzir fonemas como um nativo, e não como um falante de língua estrangeira.

Essa habilidade foi evidenciada por um experimento aqui apresentado, no qual analisamos a produção oral de falantes de Português como língua de herança e constatamos a pronúncia de fonemas característicos do PB que costumam ser difíceis de produzir quando se é estrangeiro e, mais do que isso, encontramos evidências de que há um uso de fones correspondentes às variantes regionais do Português faladas pelos pais das informantes.

Observamos ainda que, à medida que a tarefa de produção de fala ia sendo executada, as produções das informantes cada vez mais se assemelhavam com o dialeto regional do PB que possuem de herança: as variantes regionais iam emergindo em suas falas. Isso, mais uma vez, remete ao exemplo clássico da memória processual: andar de bicicleta. O indivíduo pode permanecer anos sem pedalar que a habilidade não será perdida; é provável que haja uma dificuldade ao retomar a atividade e ele pode cambalear e demorar para se equilibrar. Mas, uma vez que conseguir se estabilizar, sairá pedalando como se nunca tivesse interrompido a prática.

Nossa pesquisa está sendo desenvolvida no âmbito do Português como língua de herança. Mas entendemos que o que observamos pode ser relevante em qualquer situação de língua de herança.

As repercussões dessa característica dos falantes de LH no âmbito da família e da escola podem ser resumidas no fato de que a herança que constitui a língua da comunidade de origem precisa ser valorizada como se fosse um bem material - ela representa vantagem competitiva para o aprendiz e incentivar o contato dele com a língua na primeira infância é válido e relevante para seu futuro.

Divulgar esse tipo de achado de pesquisa ao público interessado - professores e familiares - pode tornar a língua de herança algo mais desejável e valorizado. Para os professores, saber dessa vantagem pode dar-lhes um incentivo para valorizar esse aluno, que às vezes fica desanimado. Mostrar que ele é portador de uma cultura, dar-lhe oportunidade de 


\section{$=\mathrm{T} R A M A=$}

saber mais sobre ela, de escutar mais o sotaque da própria região personaliza a experiência de aprender uma língua que talvez no momento lhe seja estranha.

Para as famílias, saber dessa informação pode dar-Ihes confiança de que, ao empregar a língua minoritária com seus filhos eles estão fornecendo não apenas um modo de eles se conectarem com a cultura de que são fruto, ainda que em uma comunidade diferente, mas também proporcionar aos filhos o domínio de uma ferramenta que, no futuro, pode representar uma chave para um emprego, uma chance de se reconectar com suas origens ou o orgulho de dizerem que conhecem a língua de seus ancestrais.

\section{REFERÊNCIAS}

BADDELEY, A; ANDERSON, M. C.; EYSENCK, M. W. M. Memória. Tradução de Cornélia Stolting. Porto Alegre: Artmed, 2011.BRITO, K. S. Influências Interlinguísticas na Mente Multilíngue: perspectivas psicolinguísticas e (psico)tipológicas. Tese (Doutorado em Letras - Estudos Linguísticos) - Setor de Ciências Humanas, Letras e Artes, Universidade Federal do Paraná. Curitiba, 2011. 274 p. Disponível em: $<$ https://acervodigital.ufpr.br/bitstream/handle/1884/27123/R\%20-\%20T\%20\%20KARIM\%20SIEBENEICHER\%20BRITO.pdf?sequence=1\&isAllowed=y>. Acesso em: 14 fev. 2019.CUMMINS, J. Heritage Language Education: a literature review. Ontario Inst. for Studies in Education, Ontario Dept. of Education: Toronto, 1983. 64 p.DALMAZ, C..; NETTO, C. A. A memória. Cien. Cult. São Paulo, v. 56, n. 1, p. 30-31, jan./mar. 2004. Disponível em: $<$ http://cienciaecultura.bvs.br/scielo.php?script=sci_arttext\&pid=S000967252004000100023\&lng=en\&nrm=iso>. Acesso em: 28 out. 2018.

DOI, E. T. O ensino de japonês no Brasil como língua de imigração. Estudos Lingüísticos. XXXV. Campinas, 2006. p. 66-75.

FLORES, C.; MELO-PFEIFER, S. O conceito "Língua de Herança" na perspectiva da Linguística e da Didática de Línguas: considerações pluridisciplinares em torno do perfil linguístico das crianças luso descendentes na Alemanha. Revista Domínios de Lingu@gem. São Paulo, v. 8, n. 3, p. 16-45, 2014. Disponível em: $<$ http://www.seer.ufu.br/index.php/dominiosdelinguagem/article/view/24736/15191>. Acesso em: 17 ago. 2018.

FONSECA, A. A.; WEISS, D. B.; DUTRA, M. C. P. Memória fonológica de falantes de português brasileiro como língua de herança. Revista Domínios de Lingu@gem. São Paulo, v. 12, n. 2, p. 1267-1293, 2018. Disponível em: <http://www.seer.ufu.br/index.php/dominiosdelinguagem/article/view/40099/22388>. Acesso em: 28 ago. 2018.

GONTIJO, V.; SILVA, G. V. A ansiedade no aprendizado de Português como Língua Estrangeira e Português como Língua de Herança. In: SILVA, K. A.; SANTOS, D. T. (Orgs.) Português como Língua (Inter)Nacional: faces e interfaces. Campinas: Pontes, 2016. p. $47-67$.

IZQUIERDO, I. et al. Memória: tipos de mecanismos - achados recentes. Revista USP. São Paulo, n. 98, p. 10-16, jun./ jul./ ago. 2013. Disponível em <http://www.revistas.usp.br/revusp/article/view/69221/71685>. Acesso em 17 ago. 2018.

JASINSKA, K. K. et al. Bilingualism yields language-specific plasticity in left hemisphere's circuitry for learning to read in young children. Neuropsychologia. USA, v. 98, p.24-45, 2017.

KLEIN, D. et al. Age of language learning shapes brain structure: a cortical thickness study of bilingual and monolingual individuals. Brain and Language. USA, v. 131, p. 20-24, 2014.

LICO, A. L. C. Ensino do Português como Língua de Herança: Prática e Fundamentos. Revista SIPLE. Brasília, n.1, ano 2, 2011. Não paginado. Disponível em:

$<$ http://www.siple.org.br/index.php?option=com_content\&view=article\&id=177:2-ensino-do-portugues-comolingua-de-heranca-pratica-efundamentos\&catid=57:edicao-2\&ltemid=92>. Acesso em: 17 ago. 2018. MONARETTO, V. N. O.; QUEDNAU, L. R.; HORA, D. As consoantes do Português. In: BISOL, L. (Org.) Introdução a estudos de fonologia do português brasileiro. 3a Ed. Porto Alegre: EDIPUCRS, 2001. p. 195-228. NORTON, B. Identity and language learning: gender, ethnicity and educational change. Londres: Longman, 2000.

OLIVEIRA, K. C. S.; LEITE, M. A.; SILVA, P. C. D. Memória. Cadernos CESPUC. Belo Horizonte, n. 23. p. 1929, 2013.

SOLÉ, Y. Consideraciones pedagógicas en la enseñanza del español a estudiantes bilingues. In: VALDÉS, G.; LOZANO, A.; GARCÍA-MOYA, R, (Orgs.) Teaching Spanish to Hispanic bilingual: issues, aims, and methods. New York: Teachers College Press, 1981. p. 21-29

SOUZA, A.; BARRADAS, O. Português como língua de herança: políticas linguísticas na Inglaterra. Revista SIPLE. Brasília, n. 1, ano 4, 2013. Não paginado. Disponível em: <http://www.siple.org.br/index.php?option=com_content\&view=article\&id=297:portugues-como-lingua-deheranca-politicas-linguisticas-na-inglaterra\&catid=69:edicao-6\&ltemid=112>. Acesso em: 28 ago. 2018. 
SOUZA, A. Como as identidades linguística e cultural são influenciadas pela imigração. In: SOUZA, A. (Org.). Português como Língua de Herança em Londres: recortes em casa, na igreja e na escola. Campinas: Pontes, 2016. p. 21-30.

SOUZA, A. Maternidade e imigração: um foco no planejamento linguístico familiar. In: SOUZA, A. (Org.).

Português como Língua de Herança em Londres: recortes em casa, na igreja e na escola. Campinas: Pontes, 2016. p. 11-51.

XAVIER, G. F. Memória, individualidade e inconsciente como expressões do funcionamento de redes nervosas: uma breve especulação. Revista USP. São Paulo, n.98, p. 31-40, jun./ jul./ ago. 2013. Disponível em: <https://www.revistas.usp.br/revusp/article/view/69223/71687>. Acesso em: 28 out. 2018.

XAVIER, G. F. A Modularidade da Memória e o Sistema Nervoso. Psicologia USP. São Paulo, v.4, n. 1-2, p. 61115, 1993. Disponível em: <http://www.revistas.usp.br/psicousp/article/view/34473>. Acesso em 28 out. 2018.

Recebido em 31-10-2018. Aceito em 18-02-2018. 